\title{
GENDER ASPECTS OF EMPATHY IN ONLINE LEARNING OF ADOLESCENTS
}

\author{
NINA PIDBUTSKA \\ Department of Pedagogy and Psychology of Social Systems Management, \\ National Technical University "Kharkiv Polytechnic Institute"; Kharkiv, \\ Ukraine \\ E-mail: podbutskaya_nina@ukr.net \\ ORCID: 0000-0001-5319-1996

\section{YULIIA DEMIDOVA} \\ Department of Pedagogy and Psychology of Social Systems Management, \\ National Technical University "Kharkiv Polytechnic Institute"; Kharkiv, \\ Ukraine \\ E-mail: dem-ula@ukr.net \\ ORCID: 0000-0002-8295-5972

\begin{abstract}
ANASTASIIA KNYSH
Department of Pedagogy and Psychology of Social Systems Management, National Technical University "Kharkiv Polytechnic Institute"; Kharkiv,

Ukraine

E-mail: n_knysh@ukr.net

ORCID: 0000-0003-0211-2535
\end{abstract}

\begin{abstract}
Aim. The aim of the article is to present the results of a study of gender-related features of the connection between empathy and performance of adolescents during online learning. The main objectives of the study are as follows: defining criteria for online learning success; holding expert assessment of success of online learning of adolescents; studying correlation between the level of empathy and success of online learning in groups of male and female.

Methods. The study participants consist of 50 teenagers from a secondary school in Kharkiv (Ukraine) and their 10 teachers. The study uses the following methods: 1) expert assessment; 2) psychological testing (Mehrabian and Epstein Questionnaire); 3) statistical methods. The following is used for statistical data processing: descriptive statistics methods (to measure the percentage of people with different levels of empathy and different levels of online learning performance); Pearson's $\chi 2$ consistency criterion- (to compare data distributions in groups of female and male participants by all study indicators); Spearman's correlation analysis (to investigate the correlation
\end{abstract}


between the level of empathy and the level of successful performance of online learning of adolescents).

Results. During the study, the aim has been achieved and all the objectives have been fulfilled, in particular: 1) "involvement in online learning" and "quality of online learning" are defined as criteria for online learning successful performance; 2) expert assessment of the study results is carried out, allowing us to determine that female participants show mainly medium and high levels of online learning performance, while male participants show low and medium-level results; 3) it is determined that the correlation between the level of performance of online learning and empathy in the group of girls is higher than in the group of boys.

Conclusions. The study shows that the development of online courses requires not only the use of modern technological and methodological approaches, but also taking into account the gender-related and personal traits of students.

Key words: online learning, empathy, academic performance, adolescents, distance learning, online course development, education, personality development.

\section{INTRODUCTION}

The global pandemic in 2020 affected all areas of public life and left a special footprint on the education system. Teachers and students around the world were forced to adapt to the new online learning environment in a short time. Indeed, online learning elements have been widely used in education before (online testing, webinars, video lectures), but they have always been applied as a supplement to the usual format of educational communication (Palvia et al., 2018). Recent events have forced participants of the educational process to build new relationships solely online.

In the first weeks of the pandemic, the main issue seemed to be technical ignorance and material unpreparedness of participants in the educational process for online learning (Yarovaya \& Bogatskaya, 2020). But high-speed Internet connection from cell phone operators and a wide range of video communications tools have allowed teachers and students to quickly find platforms to interact. However, it has brought up other issues:

- decreased motivation to learn among adolescents;

- high percentage of absences without good reasons;

- low level of learning satisfaction;

- decreased general level of knowledge.

Students whose parents simply sent them to school did not have much choice regarding attendance. In the online format, students can choose to attend classes or not almost every hour. Very often this choice is not made in favour of classes.

Of course, such a decline in the level of interest in learning could be explained by the methodological unwillingness of teachers to implement quality education. After all, online learning requires its own methods of forming and keeping motivation, its own rules of interaction, which can be worked out only with experience. However, it should be noted that the issues of low motivation are faced by the same students, regardless of the teacher 
holding classes (Rasmitadila et al., 2020). This leads to the idea that there are certain personality traits that determine the reluctance of individual students to participate actively in online learning and, as a result, a decline in academic performance.

Such personality traits should obviously be related to the interpersonal interaction of students. A number of studies have shown that empathy is a characteristic of learning success. Empathy creates a solid foundation for productive interaction of participants in the educational process and determines the motivation for further learning. It should be noted that girls in adolescence have better developed empathy compared to boys (J. Van der Graaff et al., 2018).

The hypothesis of the study is that a statistically significant correlation between the level of empathy and the level of success of online learning among teenage girls is higher than among teenage boys. To prove this assumption, we have designed the study described below.

\section{AIM OF THE RESEARCH}

The purpose of the article is to present the results of a study of genderrelated features of the correlation between empathy and performance of adolescents during online learning.

The main objectives of the study are as follows:

- Defining criteria for online learning successful performance;

- Implementing expert assessment of success of online learning among adolescents;

- Studying the correlation between the level of empathy and success of online learning in groups of male and female.

\section{METHODS}

The study was performed during the quarantine restrictions (March-June 2020) on the basis of the secondary school in Kharkiv (Ukraine) with the involvement of adolescents and their teachers. The study involved students of two classes, comprising: 25 girls (mean age 12.7 years) and 25 boys (mean age 12.6 years). The teachers who taught these children acted as experts. In particular, the study engaged 10 teachers (8 women and 2 men) who teach special subjects and were involved in the process of online teaching.

The following methods were used in the study: 1) expert assessment; 2) psychological testing; 3) statistical methods (descriptive statistics, method of comparing data distributions, correlation analysis).

The Mehrabian's and Epstein's emotional response scale was used to assess the level of empathy.

Expert assessment was used to study the success of online learning among the adolescents who participated in the study. It should be noted that online 
learning was carried out in the following forms:

- Online classes via video conferencing;

- Doing home assignments and uploading them to the school's online platform;

- Passing tests in the form of online tests.

Thus, to assess the performance of online learning, school experts were asked to assess them according to the following criteria:

- Attendance of online classes;

- Activity of participation in online classes;

- Timeliness of home assignments;

- Quality of home assignments;

- Timeliness of tests;

- Quality of tests

Each of the criteria was evaluated by the experts on a 10-point scale: where 1 is very bad and 10 is excellent. Based on the calculation of the arithmetic means of the first, third and fifth criteria, the grade "Involvement in online learning" was given, and based on the arithmetic means of the second, fourth and sixth criteria, the grade "Quality of online learning" was assigned. Thus, each student received two grades reflecting different aspects of their success in online learning. The results on both scales were considered by three levels: low (1-3 points), medium (4-7 points), high (8-10 points).

The following is used for statistical data processing:

- Methods of descriptive statistics are applied to measure the percentage of students with different levels of empathy and different levels of performance in online learning.

- Pearson's $x^{2}$ consistency criterion is used to compare data distributions in groups of girls and boys for all study indicators.

- Spearman's correlation analysis is used to examine the correlation between the level of empathy and the level of performance of adolescents in online learning.

\section{RESEARCH RESULTS}

During the study, the teachers were asked to assess the involvement of their students in online learning and the quality of online learning. After the expert assessment, all results were summarised separately for groups of girls and boys (Table 1 ).

It was determined that the girls showed mostly medium (40\%) and high $(36 \%)$ level of involvement in the educational process. The teachers noted that the vast majority of teenage girls attended all classes, and if they missed some, it was only for good reasons. In fact, the girls' attitude towards online learning is as serious as their attitude towards regular school classes. Moreover, the teachers noted that girls with a high level of involvement do not just attend all classes, they take an active part in classes, are not afraid to ask additional ques- 
tions, offer new topics for discussion, quickly navigate through the possibilities of self-expression, for example, they use a video conference chat to ask questions without interrupting the teacher.

Table 1

Distribution of respondents by level of development of online learning performance indicators

\begin{tabular}{|c|c|c|c|c|}
\hline \multirow{2}{*}{ Indicator } & \multicolumn{3}{|c|}{ Number of people $(\%)$} & \multirow{2}{*}{$\begin{array}{c}\chi^{2} \\
\text { Pearson }\end{array}$} \\
\hline & Low level & Medium level & High level & \\
\hline \multicolumn{5}{|c|}{ Involvement in online learning } \\
\hline Girls & 24 & 40 & 36 & \multirow{2}{*}{$10.4^{* *}$} \\
\hline Boys & 32 & 52 & 16 & \\
\hline \multicolumn{5}{|c|}{ Quality of online learning } \\
\hline Girls & 16 & 52 & 32 & \multirow{2}{*}{$13.186^{* *}$} \\
\hline Boys & 36 & 48 & 16 & \\
\hline
\end{tabular}

Note: Significance level: ${ }^{* *}$-p $\leq 0.01$

Source: own research.

The boys mostly show the medium and low level of online learning performance: they are more likely to miss classes for no good reasons, participate in classes with their camera off, are less likely to ask questions and initiate discussions, and make less of a contribution to the group tasks. Comparison of the distributions of the results of the expert assessment shows that the results of girls are significantly higher both in terms of involvement in online learning $\left(\chi^{2}=10.4, p \leq 0.01\right)$ and in terms of quality of online learning $\left(x^{2}=13.186, p \leq 0.01\right)$.

Thus, we see that the issues of distance learning mentioned at the beginning of the article primarily affect teenage boys. Online learning organisation features create conditions under which they often drop out of the educational process and are left alone with their beliefs, fears and doubts. These results indicate the need to create such online learning conditions in which the boys would not be left alone, but get involved in discussions.

Since earlier studies have shown that learning performance is related to empathy, a study was conducted on the level of empathy of girls and boys (Table 2).

Table 2

Distribution of respondents by level of empathy

\begin{tabular}{|c|c|c|c|c|}
\hline \multirow{2}{*}{ Indicator } & \multicolumn{3}{|c|}{ Number of people (\%) } & \multirow{2}{*}{$\begin{array}{c}X^{2} \\
\text { Pearson }\end{array}$} \\
\hline & Low level & Medium level & High level & \\
\hline Girls & 20 & 36 & 44 & 9452 ** \\
\hline Boys & 32 & 44 & 24 & 9.452 \\
\hline
\end{tabular}

Note: Significance level: ${ }^{* *}$-p $\leq 0.01$

Source: own research. 
High levels of empathy are most common in the group of girls (44\%), which is reflected in their greater interest in the experiences and thoughts of others. This focus on empathy supports the deep involvement of girls in interpersonal relationships, both with classmates and with teachers. That is why they have at least one big reason to attend online classes - the need to keep in touch with others. Active participation in classes allows girls to exchange views with others and feel supported. Such an interest in maintaining interpersonal relationships can sometimes compensate for the low interest in the subject.

The medium level of empathy $(44 \%)$ is most common in the group of boys. Of course, boys are not emotionless and also need interpersonal interactions. In addition, they feel the need for emotional distance from others and use online learning as an opportunity to "move to a safer distance", which can be manifested in silent participation in the classroom, or in participation with their camera off. At the same time, such emotional distance completely eliminates the possibility of contact with others and makes online learning uninteresting and emotionally cold.

Comparison of the distribution of empathy results in the groups of girls and boys reveals significant differences $\left(\chi^{2}=9.452, p \leq 0,01\right)$. This study indicates that among the girls there are significantly more respondents with high and medium levels of empathy, and among boys there are more respondents with medium and low levels of empathy.

The correlation analysis was performed to determine connections between online learning performance indicators and empathy (Table 3).

Table 3

Correlation matrix

\begin{tabular}{ccc}
\hline Indicators & Girls & Boys \\
\hline Involvement in online learning & $0.514^{* *}$ & $0.437^{*}$ \\
Quality of online learning & $0.451^{*}$ & 0.281 \\
\hline
\end{tabular}

Note: Significance level: ${ }^{*} \mathrm{p} \leq 0.05,{ }^{* *}-\mathrm{p} \leq 0.01$

Source: own research.

In the group of girls, positive significant correlations were found between the level of empathy and indicators of online learning performance. This means that empathetic girls are more involved in the distance learning process and have higher grades. Their motivation to take an active part in the educational process leads to greater academic performance and creates a basis for future academic success.

There is moderately significant correlation between involvement in online learning and empathy in the group of boys. Thus, more empathetic boys are more involved in learning. However, there is no significant correlation between the quality of online learning and empathy in the group of boys. 


\section{CONCLUSIONS AND DISCUSSION}

During the study, the aim has been achieved and all the objectives have been fulfilled, in particular: 1) "involvement in online learning" and "quality of online learning" are defined as criteria for online learning successful performance; 2) expert assessment of the study results is carried out, allowing us to determine that female participants show mainly medium and high levels of online learning performance, while male participants show low and mediumlevel results; 3) it is determined that the correlation between the level of performance of online learning and empathy in the group of girls is higher than in the group of boys.

Analysis of expert assessments and interviews with participants in the educational process allows the conclusion that during the last year there has been a huge breakthrough in the formation of a new type of relationship between participants in the educational process, namely, online relationships that are quite similar in nature to those described by A. Kobylarek (2019) in the context of the development of science. Those teachers who are able not only to transfer educational technology to the Internet communication space, but are ready to find new unique forms of interactions that do not replicate offline learning, but give the online interaction new meanings, are more successful. The same notion applies for students: those who are able to express themselves and their features in a new format and find forms for self-expression are better performing.

The study has shown that girls are more involved in the online learning process. Among them, there are more of those who actively ask questions during classes, join the discussion, and do exercises. In addition, there are fewer girls who regularly miss classes. Also, there are fewer girls who receive low grades for assignments. Therefore, girls are generally more successful in online learning compared to boys. The results obtained generally correspond to the trends of recent years: PISA studies indicate that girls are more successful in school academic performance than boys (Khorramdel, 2020), which is confirmed by our study. The group of boys was found to have mostly low to medium levels of online learning performance, as well as a lower level of empathy.

Moreover, S. Martínez et al. (2019) demonstrates that girls tend to be more conscientious about the learning process due to their greater attachment to teachers and classmates. It is the relationship with others and the desire to be meaningful in the eyes of other people that make girls work alone. Our study also determines that girls show a higher level of empathy, which makes it easier for them to interact in the online communication and has a more positive effect on their overall academic performance. The correlation analysis shows that in the group of girls, the involvement and quality of online learning correlates significantly with their empathy, while in the group of boys, the relationship is found only between empathy and involvement in online learning.

The results indicate the need to take into account the personality traits of students in the design of online classes, since the stimulation of empathy can have a positive impact on the involvement of students in online learning and 
their success. M. Matthews et al. (2017) demonstrate that empathy should be taken into account and consciously included in the design of an online course to increase the likelihood of students completing the course. This data is gaining new importance now when, during the pandemic, millions of adolescents around the world have the opportunity to acquire knowledge only through distance learning, and their lack of involvement in this process can lead to such a large gap in knowledge that it will be difficult to overcome in the years to come. The development of distance learning courses for adolescents should also take into account the fact that boys are somehow having a harder time to show empathy and get engaged in the learning process, and therefore they will need additional support.

The findings of the study open new challenges and horizons for educators and psychologists working on the development of distance learning courses for adolescents and seeking to provide them with high-quality education in the online learning process.

\section{REFERENCES}

[1] Bialystok, L., \& Kukar, P. (2017). Authenticity and empathy in education. Theory and Research in Education, 16(1), 23-39. doi:10.1177/14778785177466647.

[2] Demetriou, H. (2018). Empathy, Emotion and Education. London: Palgrave Macmillan. doi:10.1057/978-1-137-54844-3.

[3] Khorramdel, L., Pokropek, A., Joo S.-H., Kirsch, I., \& Halderman, L. (2020). Examining gender DIF and gender differences in the PISA 2018 reading literacy scale: A partial invariance approach. Psychological Test and Assessment Modeling, 62(2), 179-231.

[4] Kobylarek, A. (2019). Education in the post-scientific culture. Journal of Education, Culture and Society, 10(1), 5-13. doi: 10.15503jecs20191.5.13.

[5] Matthews, M. T., Williams, G. S., Yanchar, S. C., \& McDonald, J. K. (2017). Empathy in Distance Learning Design Practice. TechTrends, 61, 486-493. https://doi.org/10.1007/ s11528-017-0212-2.

[6] Palvia, S., Aeron, P., Gupta, P., Mahapatra, D., Parida, R., Rosner, R., \& Sindhi, S. (2018). Online Education: Worldwide Status, Challenges, Trends, and Implications. Journal of Global Information Technology Management, 21(4), 233-241. doi:10.1080/1097198x.2018.1542262.

[7] Rasmitadila, R., Aliyyah, R. R., Rachmadtullah, R., Samsudin, A., Syaodih, E., Nurtanto, M., \& Tambunan, A. R. S. (2020). The Perceptions of Primary School Teachers of Online Learning during the COVID-19 Pandemic Period: A Case Study in Indonesia. Journal of Ethnic and Cultural Studies, 7(2), 90-109. http://dx.doi.org/10.29333/ejecs/388.

[8] Ratka, A. (2018). Empathy and the Development of Affective Skills. American Journal of Pharmaceutical Education, 82(10), 7192. https:// doi.org/10.5688/ajpe7192.

[9] Rodríguez-Martínez, C., \& Gallardo-Gil, M. (2020). Gender differences in school performance and attitudes toward school. Ensaio: Avaliação e Políticas Públicas em Educação, 28(108), 741-761. https://doi.org/10.1590/s0104-40362019002702235.

[10] Van der Graaff, J., Carlo, G., Crocetti, E., Koot, H. M., \& Branje, S. (2018). Prosocial Behavior in Adolescence: Gender Differences in Development and Links with Empathy. Journal of Youth and Adolescence, 47, 1086-1099. https://doi.org/10.1007/s10964-017-0786-1.

[11] Yarovaya, O., Yarovaya, L., \& Bogatskaya, E. (2020). Distance learning during coronavirus: problems and solutions. E3S Web Conferences, 210, 18051. doi: 10.1051/e3sconf/202021018051.

[12] Zembylas, M., \& Papamichael, E. (2017). Pedagogies of discomfort and empathy in multicultural teacher education. Intercultural Education, 28(1), 1-19. doi:10.1080/14675986.2017.12884 48. 